Historia

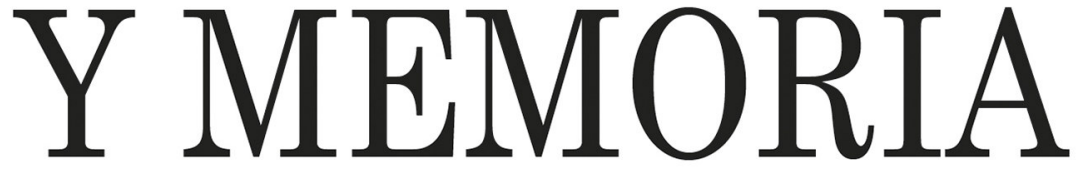

ISSN: 2027-5137 Julio - Diciembre, Año 2016 - Tunja, Colombia

La utopia de forjar una sola raza para la nación. Mestizaje, indigenismo e hispanofilia en el México posrevolucionario

Omar Fabián González Salinas Páginas: $301-330$ DOI: http://dx.doi.org/10.19053/20275137.5207

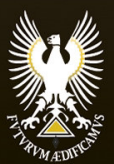




\title{
La utopía de forjar una sola raza para la nación. Mestizaje, indigenismo e hispanofilia en el México posrevolucionario*
}

\author{
Omar Fabián González Salinas ${ }^{1}$ \\ Universidad Michoacana de San Nicolás de Hidalgo - México
}

Recepción: 01/02/2016

Evaluación: 29/04/2016

Aprobación: 25/05/2016

Artículo de Investigación e Innovación.

DOI: http://dx.doi.org/10.19053/20275137.5207

\section{Resumen}

Este artículo estudia distintos proyectos de construcción nacional que durante el México posrevolucionario propusieron forjar una sola raza para asegurar un prometedor porvenir de la nación. Se abordan las ideas raciales de tres de los intelectuales que más destacaron en este ámbito, así como el discurso oficial con cual el Estado mostraba cuál era la "raza mexicana". En el estudio se utiliza la categoría "utopía",

* Una primera versión de este estudio fue presentado en el Congreso internacional «Imaginarios utópicos: pasado, presente y futuro» organizado por la Universidad Autónoma de Madrid entre los meses de septiembre y octubre del 2015.

1 Maestro en Historia por el Instituto de Investigaciones Históricas de la Universidad Michoacana de San Nicolás de Hidalgo y Licenciado en historia por la misma universidad. Es autor de diversos artículos académicos y entre sus últimas publicaciones se encuentran: «Historia, héroes y conmemoraciones como armas de lucha política. El culto a Miguel Hidalgo en tiempos de la intervención francesa en México», Anuario de historia regional y de las fronteras 21, n 2 (2016): 101-124; «Fiesta cívica y culto al 'Padre de la patria' en el Estado revolucionario (19101940)», Secuencia. Revista de historia y ciencias sociales, n 93 (2015): 162-183. Sus investigaciones se insertan en dos líneas temáticas «Nacionalismo, nación e identidad nacional» e «Historia política y cultural del México contemporáneo». Correo electrónico: omaruccio_fgs@hotmail.com 
entendida como todo proyecto a futuro que surge de la crítica y necesidad de superar los problemas del presente mediante una transformación radical. Se considera pertinente este método, pues los debates raciales estudiados tuvieron especial interés en el futuro, proponiendo distintos caminos para reconstruir la nación. Finalmente, se realiza un balance sobre el éxito o fracaso que a largo plazo ha tenido el binomio de raza y nación en México.

Palabras clave: Raza, nación, utopía, indigenismo, hispanidad, mestizaje.

\title{
The Utopia of a Single Race for the Nation. Mestizaje, Indigenism and Hispanophilia in Postrevolutionary Mexico
}

\begin{abstract}
This article studies different projects for the construction of Nation during postrevolutionary Mexico, which attempted to establish a single race in order to ensure a promising future for the Nation. We will examine the racial ideas of three of the most important intellectuals of this time, as well as the official discourse with which the State demostrated what was the "mexican race". We use the category "utopia" in the study, in defining a project set in the future that emerges from the criticism and necessity to overcome the problems of the present through radical transformation. This method is considered pertinent, due to the fact that the racial debates examined had a special interest in the future, proposing different paths to reconstruct the nation. Finally, we make a balance between the long-term success or failure of the pairing of race and nation in Mexico.
\end{abstract}

Key words: Race, nation, utopia, indigenism, hispanicity, mestizaje 


\section{L'utopie d'une seule race pour la nation. Métissage, indigénisme et hispanophilie dans le Mexique postrévolutionnaire}

\section{Résumé}

Cet article analyse différents projets de construction nationale qui pendant la période postrévolutionnaire ont proposé la constitution d'une seule race pour assurer à la nation un avenir prometteur. On étudie à ce propos les idées raciales des trois intellectuels les plus renommés, ainsi que le discours officiel avec lequel l'État montrait quelle était la «race mexicaine». Nous utilisons la notion d' «utopie», définie comme tout projet d'avenir naissant de la critique et la nécessité de dépasser les problèmes du présent par une transformation radicale. On considère pertinente cette méthode, parce que les débats raciaux étudiés ont eu une préoccupation marquée par futur, en proposant des différents chemins pour reconstruire la nation. Finalement, on effectue un bilan sur le succès ou l'échec qui à long terme a eu le binôme race et nation au Mexique.

Mots-clés: Race, nation, utopie, indigénisme, hispanité, métissage.

\section{Introducción. Nación, raza ¿y utopía?}

Desde la irrupción de la Modernidad política a finales del siglo XVIII e inicios del XIX, se comenzó a interpretar el mundo como un conglomerado de naciones, cada una habitando su propio territorio y dirigida por un Estado. Ahora sabemos que detrás de esta visión de mundo lo que realmente existió fue un proceso histórico de construcción nacional en el que cada Estado apeló al nacionalismo como un tipo de "ingeniería social" para forjar naciones donde antes no existían y dotar de una identidad nacional a quienes solían definirse en términos de identidad religiosa, étnica o según su pequeña patria. En adelante surgió la nación moderna -sujeto de soberanía de los nuevos Estados-, entendida como una comunidad en la que todos sus miembros se imaginan como iguales, comparten 
símbolos de unión, derechos y obligaciones, así como un mismo pasado, presente y futuro. En cuanto a la identidad nacional, es decir, el sentimiento de pertenencia a dicha comunidad, esta solo es posible desarrollarla mediante un proceso de socialización en el que se interioriza un imaginario colectivo que persuade al sujeto de pertenecer a determinada nación. La identidad nacional puede ser un elemento subjetivo, pero cuenta con amplia eficacia social. Todo esto implica considerar que el nacionalismo ha antecedido a las naciones y no al revés; y que tanto las naciones como las identidades nacionales han sido construcciones culturales que se encuentran en constante cambio a partir de los distintos procesos de formación del Estado, de las condiciones económicas, los medios de difusión de un relato de nación y el grado de aceptación que alcancen entre la sociedad ${ }^{2}$.

Nacionalismo, identidad nacional y nación fueron tres concepciones que desde el siglo XIX abarcaron ideas raciales que sostenían que todos los miembros de una nación compartían características biológicas, morales, culturales e intelectuales que los distinguían y diferenciaban de otras nacionalidades. Estos elementos sirvieron de base para plantear que existían razas "superiores" e "inferiores". Pronto, "la raza" se convirtió en uno de los temas de mayor importancia política, pues se le incorporó como parte de la identidad nacional bajo la cual se legitima el ejercicio del poder político en el Estado moderno ${ }^{3}$. En el caso mexicano, desde el siglo XIX se forjó la idea de una nación cuya raza era mestiza, pero que contaba con un elemento característico que no era lo español ni lo latino, sino lo indígena ${ }^{4}$.

2 Para una perspectiva teórica de los procesos de construcción nacional véase Tomás Pérez Vejo, Nación, identidad nacional y otros mitos nacionalistas (Oviedo: Ediciones nobel, 1999).

3 Pablo Yankelevich, Introducción a Inmigración y racismo. Contribuciones a la historia de los extranjeros en México (México: Colmex, 2015), 9-11; Tomás Pérez Vejo, «Extranjeros interiores y exteriores: la raza en la construcción nacional mexicana» en Inmigración y racismo..., 89-90, 102.

4 Para ahondar en las discusiones decimonónicas enfocadas en dilucidar cuál era la raza mexicana véase Tomás Pérez Vejo, España en el debate público mexicano, 1836-1867. Aportaciones para una historia de la nación (México: INAH/ENHA/ COLMEX, 2008), 153-212. 
En México -al igual que en el resto de Latinoamérica- la relación entre nación y raza llevó a concebir a los blancos como una raza superior, y a los indígenas como una inferior. De ello derivó una discriminación justificada con criterios étnicoculturales. Asimismo, la migración en América se convirtió en un proceso de selección racial: se rechazaba a los grupos considerados como racialmente inferiores, pues contaban con elementos biológicos y morales que eran "perniciosos" para la raza de la nación receptora. En el otro extremo, la migración de ciertos grupos europeos se consideró como una solución para potenciar la explotación de recursos y emprender un "mejoramiento de la raza". A todo esto eventualmente se añadió el darwinismo social, el cual dio una base "científica" al discurso racial. Con ello se fortaleció una de las ideas -i o mito?- de mayor calado de la época moderna: que el mundo está dividido en naciones y en razas ${ }^{5}$.

Pero ¿en qué punto radica la relación entre el proceso de construcción nacional y su discurso racial con las utopías? Antes de contestar esta pregunta es preciso definir qué es una utopía. Etimológicamente significa "el mejor lugar que no existe", es decir, como un sueño irrealizable y nada más. No obstante, nuevos estudios -sobre todo, los inspirados en las propuestas de Ernst Bloch- han "rehabilitado" el concepto, al entender lo utópico como un proyecto que no es un simple deseo caprichoso, sino que cuenta con la posibilidad de "poder existir" en la realidad. Ahora es que comenzamos a despojar a la utopía de la pesada losa que cargaba en hombros y que obligaba a verla como perteneciente al campo de lo idílico que nunca se materializa ${ }^{6}$.

Acorde a estas nuevas perspectivas; la crisis, la insatisfacción e inconformidad por el ordenamiento social,

5 Tomás Pérez Vejo, «Exclusión étnica en los dispositivos de conformación nacional en América Latina», Interdisciplina 2, n 4 (2014): 179-205.

6 Ruth Levitas, «La esperanza utópica: Ernst Boch y la reivindicación del futuro» Mundo siglo XXI, $\mathrm{n}^{\circ} 12$ (2008); Isidro Manuel Javier Gálvez Mora, «La función utópica en Ernst Bloch», Actas del II Coloquio de doctorandos del programa de Maestría y Doctorado en Filosofía de la Universidad Nacional Autónoma de México (México: UNAM, 2008): 51-52. 
político o económico reinante, es lo que engendra a la utopía, por ende, esta canaliza la crítica de lo existente. Si el presente representa lo que la utopía debe transformar, en el futuro ubica la esperanza del nuevo orden, ya que la realidad cuenta con una naturaleza inacabada y por lo tanto constituye un cúmulo de posibilidades. La utopía no se reduce al campo de las ideas, sino que debe aterrizarse en el mundo material para cambiar la realidad, por ello se distingue del pensamiento teórico, pues mientras que este se limita al conocimiento del mundo, la utopía busca su transformación ${ }^{7}$. No se trata tampoco de un "camino esotérico de la cultura" o una distracción de la lucha de clases, sino parte fundamental para construir el futuro ${ }^{8}$.

Ahora bien, partiendo de estos principios, es posible precisar que si las naciones y las identidades nacionales no son realidades naturales inmutables, sino productos de una cambiante "ingeniería social" que es el nacionalismo, entonces el proceso de construcción nacional puede desarrollar proyectos utópicos. Una utopía que surge de la insatisfacción por las características de la nación, que critica sus componentes y el grado de unidad nacional, y por lo tanto, propone realidades alternativas -en algunos casos bastante radicales- para forjar una nación distinta9 .

7 Adrián Calentano, «Utopía, Historia, concepto y política» Utopía y praxis latinoamericana 10, $\mathrm{n}^{\circ} 31$ (2005): 97-98; Gálvez Mora, Isidro Manuel Javier «La función utópica en Ernst Bloch» 53-54; Levitas, Ruth «La esperanza utópica» 18-23.

8 Levitas, Ruth «La esperanza utópica» 23.

9 Aclaro que en lo concerniente al concepto de «raza», lo utilizo no como categoría de análisis, pues su contenido ha quedado rebasado y se ha demostrado su falsedad. Lo empleo mas bien en el sentido en que se utilizaba en el periodo aquí estudiado cuando tenía la validez de representar una supuesta realidad. En cuanto al concepto de "utopía», este sí lo empleo como categoría de análisis -para comprender las visiones a futuro propuestas o emprendidas en el periodo en cuestión- y no como concepto histórico. Es decir, ni los personajes mencionados se autodenominaron como utopistas, ni los proyectos nacionalistas puestos en práctica fueron presentados como parte de una utopía. Esto, en buena medida se debió a que generalmente sobre este concepto ha pesado una concepción negativa en el sentido de que la expresión «utópico» era utilizada -y todavía suele hacerse- para descalificar y presentar como inviable un proyecto. Incluso, utopistas como Hitler o Stalin, hubieran rechazado ser etiquetados de esta forma por lo devaluado del concepto. Sobre los ambivalentes significados de esta categoría y su posible uso como herramienta de análisis véase Alan Knight, «El utopismo y la Revolución mexicana», en La revolución cósmica. Utopías, regiones y resultados, México 1910-1940, Editado por Alan Knight. (México: Fondo de Cultura Económica, 2015), 85-86, 90-91. 
En las siguientes páginas abordo los planteamientos raciales que surgieron en el México de inicios del siglo XX y que se convirtieron en proyectos utópicos que buscaban la unificación racial para asegurar un próspero futuro nacional. En un primer momento me ocupo del pensamiento de Andrés Molina Enríquez, Manuel Gamio y José Vasconcelos, tres intelectuales que retomaron ideas raciales sobre mestizaje, indigenismo e hispanidad, y con ellas debatieron cuál de estos elementos era, o debía ser, la esencia de la nacionalidad mexicana y cuál sería el porvenir de México si se lograba la reconfiguración racial que proponían ${ }^{10}$.

Es importante recordar que en el discurso nacionalista el conocimiento histórico es fundamental para "hacer visible" la nación, demostrar su existencia y sus supuestos orígenes remotos y nobles, por ello no extrañe que la historia nacional sea para la nación una necesidad ontológica ${ }^{11}$. No obstante, ni Molina Enríquez, Gamio o Vasconcelos se limitaron a hablar del pasado de la nación, por el contrario, la característica que los acerca a la utopía, es que debatieron sobre el presente y futuro de la nación.

La obra de estos tres personajes estuvo fuertemente influenciada por el contexto que las rodeó. En el caso de Andrés Molina Enríquez, este habló de mestizaje a los pocos años de la transición del siglo XIX al XX, cuando el discurso de modernidad y progreso del Porfiriato (1876-1910) estaba en su apogeo y presentaba a México como un país desarrollado con posibilidades de despuntar como potencia. Por otra parte, tanto Manuel Gamio como José Vasconcelos, expusieron sus ideas raciales en un periodo en que la guerra revolucionaria llegaba a su fin y comenzaba el periodo de la reconstrucción nacional.

10 El historiador Alan Knight es un tanto escéptico en cuanto a considerar proyectos utópicos en el periodo que nos ocupa, pues en lugar de utopía, dice Knight, existió un marcado pragmatismo. Según su criterio, únicamente el anticlericalismo y la reacción clerical podrían considerarse como proyectos utópicos del periodo revolucionario. $C f r$. Alan Knight, «El utopismo y la Revolución» 85-115.

11 Pérez Vejo, Tomás, Nación, identidad nacional, 117 y 124. 
Posteriormente, el artículo analiza el proyecto racial y posiblemente utópico que desarrolló el Estado mexicano después de la guerra revolucionaria. Para profundizar en el estudio de los proyectos raciales de transformación nacional, se tendrán en cuenta las siguientes preguntas guías: ¿en qué consistían las visiones utópicas que se delinearon alrededor del binomio raza-nación en el siglo XX? Si la supuesta raza perteneciente a cada nación englobaba elementos biológicos, morales, culturales e intelectuales, ¿qué papel jugarían estos componentes en la visión utópica de los personajes abordados? ¿Qué cambios (si es que los hubo) se dieron en el siglo XX respecto a la noción decimonónica de raza nacional?

Coincido con Alan Knight acerca de lo infértil que resulta un análisis sobre el pensamiento de las ideas y teorías raciales sin vincularlo con la influencia social que éstas hayan tenido ${ }^{12}$. Por ello, después de ocuparme de estos proyectos raciales presento un balance general sobre el impacto que a largo plazo han tenido estas visiones utópicas sobre la raza y la nación.

\section{Raza, nación y utopía en el pensamiento de Molina Enríquez, Manuel Gamio y José Vasconcelos}

A finales del Porfiriato y al calor del movimiento revolucionario, surgieron interesantes propuestas para reconfigurar la nación mexicana. Primeramente destacó el papel de Andrés Molina Enríquez ${ }^{13}$, quien planteaba que entre las soluciones a los problemas del país habría que considerar una nueva y más equitativa redistribución de la propiedad de la tierra, así como la creación de una nación totalmente mestiza. Su acentuada mestizofilia tenía antecedentes importantes que vale la pena mencionar, pues destacados intelectuales de la segunda mitad

\footnotetext{
12 Alan Knight, «Racismo, revolución e indigenismo: México, 1910-1940», en Repensar la Revolución mexicana, t. II (México: El Colegio de México, 2013), 49-50.

13 Molina Enríquez nació en 1868. Abogado y notario que presenció desde el inicio hasta la caída del régimen porfirista. Su constante preocupación por fortalecer a México lo llevó a plantear ideas raciales y agrarias, siendo estas últimas las más destacadas en el discurso oficial, pues fueron las que lo distinguieron cuando se convirtió en uno de los principales ideólogos de las reformas legales aplicadas a la propiedad agraria.
} 
del siglo XIX habían marcado una tendencia en identificar el mestizaje como la "verdadera" raza mexicana. Destaca el caso de Vicente Riva Palacio, quien consideraba que la época virreinal había propiciado una mezcla racial que engendró a la nacionalidad mexicana; inclusive en México a través de los siglos, la obra historiográfica que coordinó y que terminó por imponerse como el "legítimo" relato histórico mexicano, se abordaba la época colonial como la génesis del México moderno. Años más tarde, Justo Sierra enfatizaba la tarea de fortalecer a la "familia mestiza", pues en ella se encontraban los más patriotas y demócratas ${ }^{14}$.

Volviendo a Molina Enríquez, en 1908 publicó Los grandes problemas nacionales, una obra que en términos "científicos", estaba influenciada por las ideas del darwinismo social, a través del cual condensó su filiación y esperanza en un México totalmente mestizo. Y si bien criticó la estructura agraria impuesta por el gobierno de Porfirio Díaz, por otra parte su ideal racial lo llevó a proclamar una admiración por el dictador. Pensaba que el Estado solo podía estar en manos de la raza mestiza, pues en ella estaba el "elemento más fuerte, más numeroso y más patriota”. Según Enríquez, los mestizos representaban "la patria verdadera" y "entregar la dirección de los destinos nacionales a cualquiera otro de los elementos de la población, es poco menos que hacer traición a la patria. ¿Qué bien lo ha entendido así el señor Gral. Díaz!"15.

En Los grandes problemas nacionales Molina Enríquez señalaba que la nación mexicana no podía existir mientras hubiera una diversidad de razas, pues enfatizaba que ni los indígenas, ni los criollos por sí mismos podían hacer progresar al país. Estaba convencido que cada raza que habitaba el territorio nacional tenía un componente positivo (los blancos tenían mayor grado de evolución que los indígenas, pero esa

14 Agustín F. Basave Benítez, México mestizo. Análisis del nacionalismo mexicano en torno a la mestizofilia de Andrés Molina Enríquez (México: Fondo de Cultura Económica, 1992), 29-36; Enrique Florescano, Historia de las historias de la nación mexicana (México: Taurus, 2012), 344-372.

15 Andrés Molina Enríquez, Los grandes problemas nacionales (México: Centro de Estudios Históricos del Agrarismo en México, 1984), 299. 
superioridad se revertía al hablar de resistencia al medio, cualidad para la que eran mejores los indios) ${ }^{16}$, pero creía que era absolutamente necesario transformar esta heterogeneidad racial y optar por un mestizaje que unificara el origen, las costumbres, la lengua, el estado evolutivo, los deseos y las aspiraciones de la población ${ }^{17}$. Solo así, sostenía Molina Enríquez, se podría concretar una nacionalidad mexicana y se formaría "una nación propiamente dicha" que sería "soberana absoluta de sus destinos, y dueña y señora de su porvenir"18.

Tal era su fe en el mestizaje que pensaba que éste le daría a México una superioridad sobre la América anglosajona:

[...] los mestizos consumarán la absorción de los indígenas y harán la completa fusión de los criollos y de los extranjeros aquí residentes a su propia raza, (...) y a consecuencia de ello, la raza mestiza se desenvolverá con libertad. Una vez que así sea, no sólo resistirá el inevitable choque con la raza americana del Norte, sino que en se choque vencerá $[\ldots]^{19}$.

Molina Enríquez estaba dando un "giro de tuerca" a las teorías raciales que postulaban que solo las razas puras eran superiores, mientras que los híbridos estaban en una escala inferior. Estas teorías comenzaron a servir de pilar para que algunos nacionalistas mexicanos elevaran a los mestizos como raza superior (más tarde lo haría José Vasconcelos con su idea de una "raza cósmica") ${ }^{20}$. Molina Enríquez no rompe con la concepción decimonónica de que la fusión de los blancos con los indios es benéfica, pero en su pensamiento, esto no daría como resultado una raza medianamente mejor, sino superior.

Pocos años después, durante el torbellino revolucionario, Manuel Gamio apareció en escena con novedosas propuestas

16 En cuanto a los sectores negros, para Molina Enríquez éstos no le merecieron prestarles atención alguna.

17 Andrés Molina Enríquez, Los grandes problemas nacionales, 255, 300-326.

18 Andrés Molina Enríquez, Los grandes problemas nacionales, 347.

19 Andrés Molina Enríquez, Los grandes problemas nacionales, 260-261.

20 «Racismo revertido» le ha llamado Alan Knight en "Racismo, revolución e indigenismo», 77, 82 . 
sobre la nación y su composición social ${ }^{21}$. Para él, la noción de raza incluía únicamente características culturales y no biológicas, por tanto, rechazó toda teoría que propusiera que la población indígena se encontraba en un atraso cultural derivado de cuestiones biológicas y naturales. En vez de estas posturas, defendió la idea de que la miseria de este y cualquier otro sector social, se debía a condiciones socioeconómicas susceptibles de ser estudiadas, comprendidas y superadas ${ }^{22}$. Ostentaba un honesto amor por los indígenas, abogaba por "redimirlos" y convertirlos en verdaderos hermanos. Para lograr esto, predicaba lo necesario que era realizar estudios antropológicos, sociales y estadísticos como punto de partida para conocer cuantitativa y cualitativamente a la población y así el gobierno pudiera "hacer obra eficiente y de nacionalismo" 23 .

En 1916, Gamio publicó Forjando patria, libro en el que abordó las problemáticas sociales indígenas y desarrolló su tesis sobre cómo construir una verdadera nacionalidad. $\mathrm{Su}$ proyecto de reconfiguración nacional era ambicioso e implicaba una radical transformación de la sociedad a partir de tres procesos de asimilación que derivarían en una sociedad eminentemente mestiza: a) "fusión de razas", b) "convergencia y fusión de manifestaciones culturales" y c) "unificación lingüística y equilibrio económico de los elementos sociales". Cumpliéndose estas condiciones -sostenía Gamiose alcanzaría una homogeneidad racial que permitiría que en un futuro no muy lejano finalmente se encarnara "una Patria poderosa y una Nacionalidad coherente y eficiente." ${ }^{24}$.

21 Manuel Gamio fue un antropólogo y arqueólogo profesional que encabezó proyectos colectivos en el Valle de Teotihuacán. Destacó por su aplicación de los estudios de Franz Boas, los cuales consideraban que la antropología podía ayudar a comprender los problemas de una sociedad. En 1925 fue subsecretario de educación y años más tarde ocupó el puesto de primer director del Instituto Indigenista Interamericano.

22 Pablo Yankelevich, «Extranjería y antisemitismo en el México posrevolucionario», Interdisciplina 2, $\mathrm{n}^{\circ} 4$ (2014): 154.

23 Manuel Gamio, Forjando patria (México: Porrúa, 1960), 15-31.

24 Manuel Gamio, Forjando patria, 183. 
Al igual que Molina Enríquez, Gamio creía que la verdadera nación aún estaba por construirse y solo se lograría a través de una transformación radical que derivara en una sociedad donde reinara el mestizaje. Pensaba que había que hacer algo con los indígenas, quienes no podían seguir existiendo en la miseria. No los veía como un obstáculo, sino como un importante sector poblacional al que se tenía que ayudar, y habría que encontrar la forma de unirlo a la nación, pues solo de esta forma mejorarían sus condiciones. Gamio no encontró otro camino de superación para los indios que la unificación racial mestiza. A decir de Agustín Basave, este antropólogo se inclinó por "la desaparición de los indígenas, pero lo hace precisamente porque presiente que su suerte como tales no puede ser más negra; en ese sentido puede afirmarse que, más que su desaparición, Gamio quiere su reencarnación en mestizos." 25 .

Las ideas y trabajos de Manuel Gamio influyeron en que, a diferencia de lo sucedido en el Porfiriato, no solo se considerara al indio del pasado como el único que tenía importancia; una visión que años antes había justificado intentos del Estado para borrar al indio vivo ${ }^{26}$. Para Gamio ambos eran relevantes: el indio prehispánico era prueba del alto grado de civilización alcanzado, mientras que el vivo podía ser integrado a la nación mexicana mediante un paulatino proceso de asimilación. En consecuencia, los gobiernos emanados de la Revolución reforzaron la visión indigenista, prestando tanta atención al estudio de los grupos indígenas contemporáneos, como lo hacían con el rescate del pasado prehispánico. Pero antes de un nuevo encumbramiento del indigenismo, José Vasconcelos encabezó un proyecto utópico centrado en forjar una sola raza

25 Agustín F. Basave Benítez, México mestizo, 126. Señala Pablo Yankelevich que en el ideario de Gamio, tanto blancos como indios tenían mismas características anatómicas y fisiológicas, pero no así en cuanto a cultura se refiere, aspecto en que los blancos estaban más avanzados. Por este motivo, era el indio el que debía ser absorbido y no al revés. Pablo Yankelevich, «Raza y extranjería en México», (ponencia presentada en el Coloquio «Raza y política en Iberoamérica», México, El Colegio de México, 20 de octubre del 2015).

26 Para un acercamiento a la relación entre el Estado mexicano decimonónico y los grupos indígenas véase Enrique Florescano, Etnia, Estado y nación (México: Taurus, 1996). 
y una sola nación en la que el mestizaje y la hispanidad fueran los elementos de unión y fuerza.

En 1920 el revolucionario Álvaro Obregón ocupó la presidencia y con ello inició el periodo de poder del llamado "Grupo Sonora", así como la fase de reconstrucción de la Revolución mexicana. En 1921 el nuevo régimen fundó la Secretaría de Educación Pública (SEP), colocando a José Vasconcelos como su titular ${ }^{27}$. El nuevo secretario pronto despuntaría de entre el grupo de trabajo de Obregón, pues no se trataba de un simple político o burócrata, sino de todo un intelectual, un hombre con planes para refundar la nación mexicana y mirar hacia un futuro próspero.

En el ideario de José Vasconcelos se encontraba la creación de una sociedad más avanzada y superior que cualquier otra: la "raza cósmica". Predicaba que en el mundo existían cuatro razas (blanca, roja, amarilla y negra) que en Hispanoamérica se fusionarían:

[...] en el suelo de América hallará término la dispersión, allí se consumará la unidad por el triunfo del amor fecundo, y la superación de todas las estirpes. La raza nueva será la síntesis o raza íntegra, hecha con el genio y con la sangre de todos los pueblos y, por lo mismo, más capaz de verdadera fraternidad y visión realmente universal $[\ldots]^{28}$.

Vasconcelos sostenía que Hispanoamérica albergaba un mestizaje que resumía lo más positivo de todas las razas, además de contar con los componentes geográficos necesarios para que los mestizos alcanzaran su lugar como raza superior. Esa superioridad racial en un territorio privilegiado era la esencia de la utopía que Vasconcelos tenía proyectada para América Latina, pero pensaba que para poderla concretar había que añadir el componente faltante: el desarrollo

27 Filósofo que perteneció a la generación del Ateneo de la Juventud conformado por artistas e intelectuales. Desde inicios del siglo XX estuvo imbuido en la vida cultural y académica. Al momento de ocupar la Secretaría de Educación acababa de ser rector de la Universidad Nacional.

28 José Vasconcelos, La raza cósmica. Misión de la raza iberoamericana. Argentina y Brasil (México: Espasa-Calpe Mexicana, 1985), 27 y 30. 
espiritual que otorga la educación, la cultura y las artes; solo así los mestizos podrían cumplir con su llamado de dominar el mundo ${ }^{29}$.

Es en este punto que se entiende, en parte, el ímpetu que Vasconcelos puso en potenciar la educación y las artes en México. Bajo su cargo institucional se inició la campaña de alfabetización y enseñanza más ambiciosa que México hubiera conocido; los maestros fueron comparados con los misioneros evangelizadores y se les encomendó llevar la educación hasta los lugares más recónditos del país.

Respecto a las características que debía tomar la raza mexicana -así como el resto de Hispanoamérica-, Vasconcelos se inclinó por rescatar la herencia hispánica y rechazar el indigenismo, pues creía que la admiración por el pasado indígena formaba parte de un plan dirigido por Estados Unidos para eliminar la cultura hispánica del suelo americano y "reducir al pueblo mexicano al nivel de "pochos" texanos despojados de toda cultura nacional" ${ }^{30}$. Aquí estamos ante uno de los puntos más interesantes de la mestizofilia mexicana, pues se podría pensar que el mestizaje se concebía con una igual composición de elementos indígenas y españoles. Sin embargo, desde el siglo XIX se pensó que el mestizaje estaba mayormente definido por la raza indígena. Ahora, Vasconcelos daba un vuelco a esta idea y posicionaba que la hispanidad era lo que debía definir al mestizaje mexicano y latinoamericano.

Durante toda su vida intelectual el "Ulises criollo" profesó una marcada hispanofilia y una convicción de que el mestizaje desarrollado durante el virreinato era lo mejor que había sucedido en el país. Afirmaba que sin la herencia española y sin la religión católica traída de España, México solo sería un conjunto de tribus incivilizadas, incapaces de gobernar y

29 José Vasconcelos, La raza cósmica, 51.

30 David Brading «Darwinismo social e idealismo romántico. Andrés Molina Enríquez y José Vasconcelos en la Revolución mexicana», en Mito y profecía en la historia de México (México: Fondo de Cultura Económica, 2010), 202. 
cuyo único legado era el salvajismo ${ }^{31}$. En sus escritos lo único de raíz indígena que le merece admiración, era la figura de Nezahualcóyotl y Quetzalcóatl, por ser íconos la educación y la espiritualidad.

Este intelectual mostraba una admiración por el misticismo católico y el idealismo pragmático y la fuerza creadora de los incansables conquistadores, incluso reivindicaba a la figura de Hernán Cortés, a quien consideró como un constructor y padre de la nacionalidad mexicana ${ }^{32}$. Creía que la hispanidad de América era tan genuina que solo en estas tierras los aragoneses, castellanos y el vasco desaparecieron para conformar lo español, de tal forma que "lo hispánico, como nacionalidad homogénea y organizada, sólo vino a producirse en realidad, en las tierras del Nuevo Mundo.”33. Refería que el americano debía sentirse tan español como el hijo de España; identidad que no impedía que hubiera diferencias, pero siempre compartiendo una misión común que era lograr que floreciera la cultura ibérica e impidiera que en América triunfara la cultura sajona ${ }^{34}$.

$\mathrm{Su}$ ideario no solo se redujo al tema de la identidad nacional mexicana, pues también se insertó en una corriente de pensamiento que desde los primeros años de la conquista ha querido ver en América el suelo fértil para realizar las más diversas utopías; desde aquellas que han intentado formar una comunidad regida por los más altos valores cristianos, hasta las que han buscado realizar el sueño de la unión latinoamericana ${ }^{35}$. El pensamiento de Vasconcelos era

31 Basave Benítez, México mestizo, 133; Vasconcelos, La raza cósmica..., 12.

32 José Vasconcelos, Hernán Cortés. Creador de la nacionalidad (México: Ediciones Xóchitl, 1941); José Vasconcelos, «El pensamiento iberoamericano», en Ideas en torno a Latinoamérica (México: UNAM / Unión de Universidades de América Latina, 1986), 328-335.

33 Vasconcelos, Breve historia de México (México: Continental, 1956), 533.

34 Vasconcelos, La raza cósmica, 19.

35 Francesca Cantú, "América y utopía en el siglo XVI» Cuadernos de Historia moderna, anejos, $\mathrm{n}^{\circ} 1$ (2002): 45-64; Sergio Guerra Vilaboy y Alejo Maldonado Gallardo, Los laberintos de la integración latinoamericana. Historia, mito y realidad (México: UMSNH, 2002); Rafael Rojas, "Utopía y desencanto en Hispanoamérica», en Independencias y revoluciones en el Caribe. Prensa, vanguardia y nación en Puerto 
una utopía racial y nacional que, al igual que la de Molina Enríquez y de Gamio, creía en la fusión de razas para transformar la sociedad en un solo cuerpo mestizo. El futuro utópico del "Ulises criollo" llegaba al extremo de precisar que la raza mestiza sería la protagonista de una nueva era en la que Latinoamérica se convertiría en el eje rector del mundo gracias a su componente racial y espiritual.

Quizás este es el proyecto utópico latinoamericano más ambicioso -que no extravagante, pues estamos en un contexto donde el pensamiento racial hablaba de razas superiores e inferiores- que ha existido. Y nuevamente estamos ante una elevación y no degradación de los híbridos raciales.

Vasconcelos pronto tuvo oportunidad para difundir sus ideas; en 1922 se llevó a cabo la Exposición Universal de Río de Janeiro, en la que él encabezaría a la delegación mexicana. $\mathrm{Al}$ "Ulises Criollo" le disgustó que ha dicho evento México enviara una copia de la escultura del Cuauhtémoc ubicada en la avenida Reforma. Una decisión tomada por el gobierno obregonista, en la que él no pudo intervenir. Sin embargo, para el pabellón mexicano que luciría las exposiciones mexicanas, decidió que se construyera un edificio de inspiración colonial, pues pensaba que dicho en estilo era una muestra de la fusión de las talentosas manos del indígena con la técnica e inteligencia española ${ }^{36}$.

Daniel Cosio Villegas, colaborador cercano a él, escribió que Vasconcelos era el único de los intelectuales en el que confiaba el régimen, "tanto que a él solamente se le dieron

Rico y Cuba, siglos XIX y XX (Morelia: UMSNH / Red de Estudios Comparados del Caribe y el Mundo Atlántico, 2012), 27-38.

36 Mauricio Tenorio Trillo, Artilugio de la nación moderna. México en las exposiciones universales, 1880-1930 (México: FCE, 1998), 267-293. En 1936 Vasconcelos publicó su Breve historia de México, una de sus obras más hispanófilas. En ella se encuentra una reflexión histórica que rescata el relato de nación conservador del siglo XIX. Para él el pasado prehispánico estaba lleno de salvajismo, mientras que la Conquista significó la redención de decadentes culturas indígenas y la fundación de una nueva nación. El periodo independiente aparecía como una manipulación de mexicanos por parte de británicos y norteamericanos. Solo Lucas Alamán, el hispanófilo más conocido del México decimonónico, le merece una valoración positiva. 
autoridad y medios para trabajar"37. Esto explica por qué, a diferencia de Molina Enríquez y Gamio, Vasconcelos tuvo mayores oportunidades para emprender la obra utópica que vislumbraba para México y América Latina. Sin embargo, también se debe reconocer que pese a las facilidades para trabajar, su ideal de una nacionalidad mayoritariamente hispana tuvo un fugaz eco en el país. Quizás fue en los inicios del muralismo mexicano -movimiento que él inauguró como representante de un mecenazgo oficial, primero siendo rector de la Universidad de México y posteriormente desde su dirección de la SEP- donde sus ideas encontraron correspondencia.

Vasconcelos estaba convencido de que la educación, la cultura y el arte eran necesarios para que el mestizaje hispanófilo encontrara su punto de despegue para conformar a la utópica "raza cósmica". Para lograr dicho objetivo, en 1921 encargó la primera serie de murales que debían ser ejecutados en el ex convento de San Pedro y San Pablo de la ciudad de México, recinto restaurado y convertido en sala de lectura y conferencias para la Universidad Nacional. Si bien es cierto que el arte también encierra una función utópica, pues en no pocas ocasiones expresa los deseos de un futuro prometedor donde queden superados los conflictos del presente ${ }^{38}$, en el caso de estos murales, Vasconcelos no encomendó una visión a futuro, sino una interpretación del pasado y la civilización.

El siguiente conjunto mural que encargó tuvo lugar en el antiguo Colegio de San Ildefonso, que entonces albergaba a la Preparatoria Nacional. Existe la versión de que para estos murales, quien contrató y cubrió los sueldos de los pintores fue el director de la Preparatoria, el marxista Vicente Lombardo Toledano, no obstante, en la temática de las obras sobresale la influencia de Vasconcelos, quien encomendó a los pintores que

37 Citado en Enrique Krauze, Caudillos culturales en la Revolución (México: Tusquets, 2007), 119.

38 Gálvez Mora, «La función utópica en Ernst Bloch», 54. En el caso mexicano, los murales de Diego Rivera son un excelente ejemplo de cómo un artista participaba en las utopías nacionales. Para Rivera el futuro de México debía estar fundado en las ideas del marxismo-leninismo, un país reconstruido por las clases obreras y campesinas donde no existirían diferencias de clase. 
representaran los orígenes culturales, raciales e históricos de la nación. Los murales retomaron un tono de humanismo universalista y representaron el mestizaje racial y cultural. Entre 1922 y 1923 Ramón Alva de la Canal pintó el mural El desembarco de españoles y la cruz plantada en tierras nuevas, para el cual Vasconcelos pidió que se plasmara a "la gran patria": la que es compartida por latinos y sus hermanos mayores del imperio español, y que funde los lazos de sangre y de espíritu que engendraron el mestizaje ${ }^{39}$.

En 1924 Vasconcelos renunció a su cargo en la sEP; su apoyo a la rebelión Delahuertista le había valido la antipatía del Grupo Sonora en el poder. Llegó a su fin la influencia de este intelectual. Sin embargo, en 1929 el "Ulises criollo" se embarcó en una aventura política difícil de concretar: ganar la presidencia nacional siendo candidato de oposición al entonces recién creado Partido Nacional Revolucionario (PNR). Se enfrentó a la organización política que aglutinaba a las mayores fuerzas armadas del país; una superioridad de fuerza que se manifestó en las sucias elecciones que terminaron en asesinatos y manipulación de los resultados.

Pero, ¿qué habría pasado si José Vasconcelos hubiera ganado la presidencia? Habrá quien piense que puede ser ocioso detenerse a hacer este tipo de "historia ficción" contrafactual-, pero valdría la pena reparar en que de haber sido así, se hubiera impuesto una visión nacional hispanófila, al menos por el tiempo que durara su mandato. Periodo en el cual hubieran cambiado las representaciones de muchas expresiones culturales e interpretaciones históricas. Puede ser que los murales de Diego Rivera no mostraran una cruel conquista y sanguinarios conquistadores, sino a evangelizadores apostólicos y colonizadores fundadores de una nueva nacionalidad. Tal vez la identidad mexicana hubiera cambiado su interpretación heredada del siglo XIX, y en vez

39 Sobre la influencia de Vasconcelos en el muralismo mexicano véase Alicia Azuela de la Cueva, Arte y poder. Renacimiento artístico y revolución social, México 19101945 (México: Fondo de Cultura Económica / El Colegio de Michoacán, 2005), 97-98, 133-148. 
de fundamentarse en el orgullo del pasado precolombino, lo hubiera hecho en torno a la herencia hispánica y no en confrontación a esta. Pero, a fin de cuentas esto no ocurrió y su exaltación por lo hispánico y su utopía de construir una raza superior en Hispanoamérica, no prosperaron.

\section{Imposición del indigenismo en el nacionalismo oficial del México posrevolucionario ${ }^{40}$}

La inclinación tanto de Molina Enríquez, como de Gamio y Vasconcelos por el mestizaje, tenía cierta concordancia con un discurso oficial mestizófilo que desde el siglo XIX se fue tornando hegemónico, entre otras razones, porque era una forma de fortalecer la idea que el nacionalismo establece para toda nación: ser una comunidad homogénea. En este caso, el mestizaje se convirtió en la principal bandera para reivindicar la idea de que México tenía una particularidad entre el resto de naciones. Fue también una salida para ignorar la diversidad regional y étnica existente en el territorio; una estrategia con la que el Estado podía otorgar sus beneficios -educativos, de salud, de trabajo, etcétera- únicamente a la población que se apegara a sus normas: hablar la lengua española, obedecer un solo marco legal y mantener una lealtad exclusiva hacia el Estado nacional y no a una organización comunal o del tipo que fuera.

Pero tal como se señaló líneas arriba, aunque oficialmente se tenía la idea de México como una nación mestiza, no se pensaba que dicho mestizaje implicara un mismo grado de herencia cultural y racial de parte de sus componentes indígena e hispánico (en todo momento se ignoró la posibilidad de una raíz afrodescendiente). Así, después de la influencia hispanófila de Vasconcelos, renació una glorificación del pasado prehispánico como única expresión

40 En este punto es preciso definir que indigenismo es un concepto que engloba las concepciones teóricas y de conciencia que se elaboran acerca del mundo indígena desde los no indígenas. En este artículo utilizo este concepto para referirme a cómo se imaginaba el pasado prehispánico, el lugar que se le daba a los indígenas dentro de la sociedad contemporánea, así como el papel que se le asignaba al componente indígena dentro de la idea de una raza nacional. Retomo esta definición de: Luis Villoro, Los grandes momentos del indigenismo en México (México: Fondo de Cultura Económica / El Colegio Nacional, 2005), 14. 
de la raza mexicana y supuesta característica predominante del México mestizo. Esta propaganda no sólo se difundió al interior del país, pues nuevamente se le llevó al extranjero gracias a la participación de México en la Exposición Universal de Sevilla en 1929. Para la ocasión el gobierno de Plutarco Elías Calles no envió un pabellón de estilo colonial como el que había gestionado Vasconcelos en la exposición de 1922; en este caso se construyó un edificio indigenista con estilo maya tolteca y aunque en su interior hubo piezas que aludían a la hispanidad, quizás no se trataba de una nueva reconciliación con la herencia hispánica, sino una forma de hacer el pabellón más aceptable para España, el país anfitrión ${ }^{41}$.

La revaloración simbólica del indígena tomó un especial esplendor en el movimiento muralista que, entre otros objetivos, se utilizó para difundir un relato visual de la historia nacional. A decir de Itzel Rodríguez Mortellaro, el elemento prehispánico estuvo presente en distintos aspectos del movimiento muralista: "en la discusión estética, en el discurso sobre la identidad nacional, en las recreaciones históricas y antropológicas, en la reflexión filosófica y existencial, en las elaboraciones esotéricas, en las explicaciones sobre la cultura en México [...]"42. Un claro ejemplo de esto, es el mural Historia del estado de Morelos, conquista y revolución que Diego Rivera pintó entre 1929 y 1930, y que bien puede interpretarse como una versión icónica de la llamada "leyenda negra de la Conquista". Dicha obra causó el malestar de diplomáticos españoles en México y sectores hispanófilos mexicanos, pero cuando a Rivera se le cuestionaba sobre su visión hispanófoba e indigenista, él solía responder "iya apareció el gachupín!”43. Finalmente las protestas no tuvieron mayor repercusión sobre el mural, el cual no fue modificado ${ }^{44}$.

41 Tenorio Trillo, Artilugio de la nación moderna, 294-320.

42 Itzel Rodríguez Mortellaro, «Imagen prehispánica en el muralismo del siglo XX», Arqueología Mexicana 17, n 100 (2009): 63.

43 «Gachupín» es una palabra con sentido peyorativo utilizada en México para denostar al español o lo español.

44 Ricardo Pérez Montfort, «Las peripecias diplomáticas de un mural o Diego Rivera y la hispanofibia», en Imágenes e imaginarios sobre España en México, siglos XIX y 
Resulta paradójico que en medio de este contexto, en 1928 oficialmente en México se declarara el 12 de octubre (la conmemoración de la llegada de Colón a tierras que después serían llamadas "América") como el "Día de la raza". Más incongruente aún resultó que poco después de incluir esta fecha en el calendario cívico, se iniciara la construcción de un monumento dedicado a "la raza" en el cual no se celebraba a una raza hispánica o síntesis de lo indígena con lo español, sino que estaba totalmente dedicado a glorificar el pasado prehispánico (el monumento se compone de una reconstrucción piramidal indígena de 50 metros de altura y rematada por el águila azteca devorando una serpiente. Su cuerpo está adornado con motivos prehispánicos y con esculturas que rememoraban la fundación de Tenochtitlan y la resistencia mexica frente a los conquistadores). Se tenía una celebración que cada 12 de octubre conmemoraba a la raza en un día que recordaba el contacto entre hispanos e indígenas, pero los 364 días restantes prevalecía un monumento claramente proprehispanista. Una vez más el indigenismo se imponía frente a la hispanidad como característica de la raza mexicana ${ }^{45}$.

Para la década de 1930 el indigenismo ya era ampliamente aceptado como elemento de orgullo de la raza mestiza mexicana. En este contexto las visiones hispánicas no tenían cabida en el nacionalismo mexicano, de hecho, en medio de la amplia propaganda nacionalista que rodeó a la expropiación petrolera de 1938, José Vasconcelos se convirtió en objeto de ataques de aquellos que repudiaban su hispanofilia. Vale la pena agregar una extendida cita que muestra cómo se llegó a abominar su ideario y todo relato de nación de signo hispanófilo:

[...] He ahí a Ulises criollo, el Alamán de nuestros días, prototipo contemporáneo de los conservadores de abolengo,

XX (México, Editorial Porrúa / Universidad Michoacana de San Nicolás de Hidalgo / Conacyt), 465-490.

45 Para una muestra del amplio repertorio iconográfico de filiación prehispanista que ha circulado en el imaginario mexicano durante el siglo XX, véase Eduardo Matos Moctezuma, «Usos y abusos de la arqueología», Arqueología Mexicana, $\mathrm{n}^{\circ} 46$ (edición especial, 2012): 12-87. 
metidos en la Revolución para sembrar en las filas la discordia y el descontento. Aspiró a la presidencia siguiendo las huellas que dejaron el Felón de Acatempan, Anastasio Bustamante, Santa Anna y otros que (...) fueron militares al servicio de los opresores, y para proseguir la obra perversa y sofística de Alamán, sobre la 'nueva nacionalidad', execrar a los hombres-símbolos de la tradición y de la historia mexicanas; ensalzar a los vencedores y calumniar a majestuosas figuras de la patria, como a Cuauhtémoc (...) He ahí para muestra, ese escrito vil salido de la médula conservadora que es su engendro titulado 'Breve historia de México'; sus obras vomitan desprecio por todo el que no es de origen español, de ese pueblo español que obrando en nombre del trono, de la aristocracia y del Clero, clavó desde el siglo XVI al pueblo mexicano, en la más infame miseria sometiéndolo a la servidumbre y al peonaje en su propia patria; patria que le arrebataron primero y le escamotearon después $[\ldots]^{46}$.

Un punto importante y no menos paradójico de esta revaloración indigenista, es el hecho de que a los indígenas vivos no se les vio como parte activa de la nación mexicana, sino únicamente como objeto de análisis. Esto se reflejó en los principales museos fundados años después en la ciudad de México. El Museo Nacional de Historia (1944) resguardaba el pasado de un México donde lo mestizo representaba el "nosotros" y no al "otro" visto en el indígena y la hispanidad, mientras que el Museo Nacional de Antropología e Historia (1964) mostraba un pasado prehispánico y etnias convertidas en "fósiles vivientes" e intemporales, y no quedaba claro cuál era su vínculo con el México contemporáneo ${ }^{47}$.

Por lo anterior, es posible plantear que después del hispanismo de Vasconcelos, la revaloración del mestizaje desde las esferas del Estado posrevolucionario perdió una parte del componente utópico que le imprimieron Molina Enríquez, Gamio y el mismo Vasconcelos. En adelante, el

46 Recorte de periódico: «Hacia la independencia positiva» (México, D.F., abril de 1938), en Archivo del Centro de Estudios de la Revolución Mexicana «Lázaro Cárdenas» / Unidad Académica de Estudios Regionales de la Universidad Nacional Autónoma de México (ACERMLC / UAER-UNAM), Fondo Francisco J. Múgica, vol. 185, doc. 70 .

47 Tomás Pérez Vejo, «Historia, antropología y arte: tres sujetos, dos pasados y una sola nación verdadera", Revista de Indias 42, n 254, (2012): 67-92. 
mestizaje oficial más que enfocarse en buscar el despunte de una raza superior, concentró sus esfuerzos en dos objetivos: proteger, preservar y expandir el mestizaje, y revalorar lo indígena como su elemento ancestral y de orgullo nacional. Prueba de ello es el indigenismo que se acaba de explicar y el diseño de políticas migratorias de carácter selectivo que buscaban atraer al país razas benéficas, prohibir la entrada de razas que pudieran "degenerar" a la mexicana y exigir que los migrantes formaran familia mestiza ${ }^{48}$.

\section{A manera de conclusiones. Unificación racial para la nación, una utopía no lograda}

Los proyectos raciales estudiados retomaron aspectos de las concepciones de raza y nación existentes en el siglo XIX mexicano en cuanto a que presentaron la raza nacional como mestiza. Molina Enríquez planteó que tanto indios como blancos tenían aspectos biológicos y culturales distintos que debían fundirse para formar una sólida y fuerte raza mexicana totalmente homogénea. Manuel Gamio concebía que solamente existían razas distintas en desarrollo cultural, más no en lo biológico y que la fusión del indígena en la raza mestiza era la solución para mejorar sus condiciones y forjar una unidad nacional exenta de núcleos humanos con deficiencias socioeconómicas. Por su parte, Vasconcelos planteaba la formación de una nueva raza mestiza formada a partir de los mejores aspectos de cada una de las cuatro razas que, según su ideario, poblaban el mundo. Un mestizaje al que solo habría que añadirle una educación universal y una identidad hispánica y con ello se convertiría en la raza más avanzada y fuerte que dominaría el mundo. Finalmente, el nacionalismo oficial apostó únicamente por formar una raza mestiza, pero sin objetivos de forjar una raza superior a otras, tan solo enfocándose en la unidad, la preservación del mestizaje y la exaltación del indigenismo como elemento de orgullo y definición nacional.

48 Véase los estudios de Pablo Yankelevich: «Raza y extranjería» y «Extranjería y antisemitismo». 
De estos proyectos utópicos centrados en la raza nacional, podemos afirmar que ninguno, ni tampoco el mestizaje oficial, logró imponerse totalmente. La utopía vasconceliana no pudo florecer en su vertiente de la hispanidad como elemento de unificación nacional, ya que desde el siglo XIX el discurso nacionalista había creado un relato de nación en el que México era heredero del pasado prehispánico, una época de supuesta gloria aplastada por una cruel conquista ${ }^{49}$. Discurso que, como se explicó en el apartado anterior, prácticamente se volvió hegemónico hacia la segunda mitad de la década de 1920. Aunado a esto, debe reconocerse que en buena medida la identidad nacional se había construido sobre el rechazo al "otro", en este caso representado por el español. En el imaginario nacionalista, entre lo indígena y lo español existía una dicotomía difícil de romper en el corto tiempo en que Vasconcelos tuvo cierto control de los medios oficiales.

En cuanto a su proyecto utópico de forjar una raza avanzada hispanoamericana, esto simplemente no tuvo mayor eco, pues como se explicó líneas atrás, Vasconcelos pronto se convirtió en un intelectual incómodo para el régimen, y esto sin contar que la experiencia internacional del nazismo y la segunda guerra mundial, así como el avance de las ciencias que rebasaron el darwinismo social y el determinismo biológico, fueron motivos suficientes para condenar al fracaso toda idea sustentada en la diferenciación racial y la búsqueda de una raza superior.

Por otra parte, recordemos que tanto Molina Enríquez, Gamio, Vasconcelos y el nacionalismo oficial posrevolucionario, compartieron -a su modo- el ímpetu por la mestizofilia. Respecto a esto y aunque dicha idea de nación mestiza sigue

49 En el México de la primera mitad del siglo XIX prevalecieron dos relatos de nación distintos: uno liberal que sostenía que México era una nación con origen en el pasado prehispánico, muerto con la Conquista y resucitado con la Independencia. El segundo relato precisaba que México nación con la Conquista, que revaloraba el pasado español y que concebía la Independencia como parte de un crecimiento "natural" de una nación que se desprendía de su madre patria, España. Finalmente, las vicisitudes políticas impusieron el relato de nación liberal como el que fielmente representaba a México. Al respecto véase Pérez Vejo, Tomás, España en el debate público mexicano. 
imperando en el discurso oficial, así como también buena parte de la población piensa que México es un país mestizo -cultural y racialmente-, vale la pena recalcar que dicha idea es confrontada en el día a día por la innegable diversidad étnica y lingüística existente en el territorio nacional. Es indudable que la utopía, una nación homogénea bajo el sello del mestizaje ha sucumbido ante la complejidad social. Asimismo, habría que considerar que en el pasado reciente (1994) el levantamiento indígena del Ejército Zapatista de Liberación Nacional (EZLN) dejó en claro que existen grupos étnicos que no se sienten representados ni incluidos en el Estado nacional. La propuesta de Gamio de una "absorción" paulatina de los indígenas en una nación mestiza, fue un proyecto fracasado. Con semejante contexto ¿realmente se puede hablar de la unidad de lengua, raza y tradiciones por la que se pugnaba? Quizás el EZLN no tuvo el impacto bélico que se especuló, pero su irrupción fue un grito que hizo voltear la mirada a este tema y considerar seriamente que la homogeneidad racial y nacional no existe.

Por otra parte, después de la valoración hispanófila de Vasconcelos, el discurso oficial retomó y acrecentó el indigenismo como elemento distintivo del mestizo mexicano. Sin embargo, ese proyecto de nación mestiza orgullosa de su componente indígena tampoco fue concretado e incluso cae en enormes contradicciones. Por ejemplo, aunque hoy en día sigue existiendo una retórica nacionalista que reivindica al pasado prehispánico, este sentimiento de orgullo nacional contrasta fuertemente con un México que ostenta criterios racistas y estereotipos de belleza que rechazan lo indígena contemporáneo y que han conducido a situaciones en las que el uso de la palabra "indio" sirve para denigrar e insultar. Más allá del culto por el pasado precolombino, no hay realmente una sociedad fundada en valores de respeto e igualdad hacia las comunidades indígenas ${ }^{50}$. El fortalecimiento de los movimientos de reivindicación indígena no solo revela el fracaso

50 Luis Villoro refiere a este fenómeno como la «paradoja del indigenismo» reflejada en cómo lo indígena puede considerarse como lo propio, pero a la vez, como lo extraño. Luis Villoro, Los grandes momentos, 229-238. 
del mestizaje, también el poco diálogo y desconocimiento que priva entre pueblos indígenas y el Estado nacional.

Habría que reflexionar en que los nacionalismos son falsas conciencias que tratan de reducir la pluralidad de una población a la existencia de una sola identidad, pero en el camino suelen chocar con una reacia diversidad social (el caso mexicano es de los más representativos). Y no es que la homogeneidad cultural sea algo imposible, pero para tal efecto es necesario poner en marcha un sistemático y constante uso de instrumentos como la educación, las artes, los mitos y los rituales de socialización que provoquen lo que bien puede denominarse como genocidio cultural. Sin embargo -y afortunadamente- hasta ahora dichos elementos no han logrado borrar las huellas de la pluralidad social.

Hemos visto que a inicios del siglo XX mexicano surgieron utopías nacionalistas que hablaron de un futuro próspero que el país podía alcanzar si se lograba una unificación racial. Sin embargo, cabe preguntarnos si es que acaso en el presente los nacionalismos siguen girando en la órbita de las utopías de los más variados tipos. Me viene a la mente el caso del nacionalismo catalán que ha puesto en jaque a España -como Estado y como nación- y está vislumbrando un próspero porvenir para Cataluña en caso de alcanzar su independencia. Esto parece ser un imaginario utópico que implica la radical ruptura y refundación de una región y una sociedad. Una utopía peligrosa y que podría tornar hacia una distopía, pues no está tomando en cuenta -al menos no muy seriamente- las repercusiones políticas y económicas que desencadenaría su separación de España.

Ante estas situaciones, creo que los científicos sociales tenemos que ser críticos con los proyectos a futuro que cada sociedad y sus gobiernos se plantean, pues algunos pueden encarnar utopías viables y necesarias, pero otros pueden derivar en utopías mal planeadas y por tanto, riesgosas nuevamente la utopía puede volcarse hacia la distopía-. 
Retomo una frase de Alan Knight, quien señala que "los experimentos utópicos -tanto 'micro' como, a fortiori, 'macro'- pueden ser muy interesantes para estudiar, pero son muy desagradables para vivirlos en carne propia"51. Rescato estas palabras porque precisamente las utopías raciales aquí analizadas no hubieran sido muy agradables para vivirlas, pues cumplirlas hubiera implicado acabar con la rica diversidad étnica y cultural.

Por último, quisiera precisar que el argumentar, como lo hace la ideología nacionalista, que el mestizaje es la esencia del mexicano, o discutir si este mestizaje tiene mayores elementos hispanos o indígenas, es un debate que si bien sirve para dotar de identidad, no menos cierto es que se trata de una discusión con nulo rigor científico que nubla la comprensión de nuestra realidad histórica y contemporánea.

\section{Fuentes documentales}

Archivo del Centro de Estudios de la Revolución Mexicana «Lázaro Cárdenas» / Unidad Académica de Estudios Regionales de la Universidad Nacional Autónoma de México (ACERMLC / UAER-UNAM), Jiquilpan, Michoacán - México. Fondo Francisco J. Múgica.

\section{Bibliografía}

Azuela de la Cueva, Alicia. Arte y Poder. Renacimiento artístico y revolución social. México 1910-1945. México: Fondo de Cultura Económica / El Colegio de Michoacán, 2005.

Basave Benítez, Agustín F. México mestizo. Análisis del nacionalismo mexicano en torno a la mestizofilia de Andrés Molina Enríquez. México: Fondo de Cultura Económica, 1992.

Brading, David. «Darwinismo social e idealismo romántico. Andrés Molina Enríquez y José Vasconcelos en la Revolución

51 Alan Knight, «El utopismo y la Revolución» 115. Las cursivas son de la obra citada. 
mexicana» En Mito y profecía en la historia de México. México: Fondo de Cultura Económica, 2010. 170-203.

Calentano, Adrián. «Utopía, Historia, concepto y política», Utopía y praxis latinoamericana $\mathrm{X}, \mathrm{n}^{\circ} 31,(2005)$ : 93-114.

Cantú, Francesca. "América y utopía en el siglo XVI», Cuadernos de Historia moderna. anejos, $\mathrm{n}^{\circ} 1$ (2002): 45-64.

Florescano, Enrique. Etnia, Estado y nación. México: Taurus, 1996. Historia de las historias de la nación mexicana. México: Taurus, 2012.

Gálvez Mora, Isidro Manuel Javier. «La función utópica en Ernst Bloch». En Actas del II Coloquio de doctorandos del programa de Maestría y Doctorado en Filosofía de la Universidad Nacional Autónoma de México. México: UNAM, 2008. 51-60.

Gamio, Manuel. Forjando patria. México: Porrúa, 1960.

Guerra Vilaboy, Sergio y Alejo Maldonado Gallardo. Los laberintos de la integración latinoamericana. Historia, mito y realidad. México: UMSNH, 2002.

Knight, Alan. «Racismo, Revolución e indigenismo: México: 19101940». En Repensar la Revolución mexicana, t. II, editado por Centro de Estudios Históricos del Colegio de México. México: El Colegio de México, 2013. 49-108.

«El utopismo y la Revolución mexicana» En

La revolución cósmica. Utopías, regiones y resultados, México 1910-1940. México: Fondo de Cultura Económica, 2015. 85105.

Krauze, Enrique. Caudillos culturales en la Revolución mexicana. México: Tusquets, 2007.

Levitas, Ruth. «La esperanza utópica: Ernst Bloch y la reivindicación del futuro», Mundo Siglo XXI, n 12 (2008): 15-29.

Matos Moctezuma, Eduardo. "Usos y abusos de la arqueología», Arqueología Mexicana, $\mathrm{n}^{\circ} 46$ (edición especial, septiembre 2012): 12-87. 
Molina Enríquez, Andrés. Los grandes problemas nacionales. México: Centro de Estudios Históricos del Agrarismo en México, 1984.

Pérez Montfort, Ricardo. «Las peripecias diplomáticas de un mural o Diego Rivera y la hispanofobia». En Imágenes e imaginarios sobre España en México, siglos XIX y XX, coordinado por Agustín Sánchez Andrés, Tomás Pérez Vejo y Marco Antonio Landavazo. México: Porrúa / IIH-UMSNH / CONACyT, 2007. 465-490.

Pérez Vejo, Tomás. España en el debate público mexicano, 18361867. Aportaciones para una historia de la nación. México: INAH / ENAH / El Colegio de México, 2008.

. «Exclusión étnica en los dispositivos de conformación nacional en América Latina», Interdisciplina 2, $\mathrm{n}^{\circ} 4$ (2014): 179-205.

«Extranjeros interiores y exteriores: la raza en la construcción nacional mexicana», En Inmigración y racismo. Contribuciones a la historia de los extranjeros en México, coordinado por Pablo Yankelevich. México: El Colegio de México, 2015. 89-124.

. «Historia, antropología y arte: tres sujetos, dos pasados y una sola nación verdadera», Revista de Indias 42, $\mathrm{n}^{\circ} 254,(2012) 67-92$.

Nación, identidad nacional y otros mitos nacionalistas. Oviedo: Ediciones Nobel, 1999.

Rojas, Rafael. "Utopía y desencanto en Hispanoamérica» En Independencias y revoluciones en el Caribe: Prensa, vanguardia y nación en Puerto Rico y Cuba, siglos XIX y XX, Coordinado por Leticia Bobadilla González y Martín López Ávalos. Morelia: Universidad Michoacana de San Nicolás de Hidalgo / El Colegio de Michoacán / Red de Estudios Comparados del Caribe y Mundo Atlántico, 2012. 27-38.

Rodríguez Mortellaro, Itzel. «Imagen prehispánica en el muralismo del siglo XX», Arqueología Mexicana 17, n 100, (2009): 62-69. 
Tenorio Trillo, Mauricio. Artilugio de la nación moderna. México en las exposiciones universales, 1880-1930. México: Fondo de Cultura Económica, 1998.

Vasconcelos, José. Breve historia de México. México: Continental, 1956.

«El pensamiento iberoamericano» En Ideas en torno de Latinoamérica, vol. I. México: Universidad Nacional Autónoma de México / Unión de Universidades de América Latina, 1986. 328-335.

Hernán Cortés. Creador de la nacionalidad. México: Ediciones Xóchitl, 1941.

- La raza cósmica. Misión de la raza iberoamericana. Argentina y Brasil. México: Espasa-Calpe Mexicana S.A., 1985.

Villoro, Luis. Los grandes momentos del indigenismo en México. México: Fondo de Cultura Económica / El Colegio Nacional, 2005 .

Yankelevich, Pablo. «Extranjería y antisemitismo en el México posrevolucionario» Interdisciplina $2, \mathrm{n}^{\circ} 4$ (2014): 179-205.

Introducción a Inmigración y racismo. Contribuciones a la historia de los extranjeros en México, coordinado por Pablo Yankelevich, 9-27. México: El Colegio de México, 2015.

«Raza y extranjería en México». Ponencia presentada en el Coloquio "Raza y política en Iberoamérica», México, El Colegio de México, 20 de octubre del 2015.

\section{Citar este artículo:}

González Salinas, Omar Fabián. «La utopía de forjar una sola raza para la nación. Mestizaje, indigenismo e hispanofilia en el México posrevolucionario». Historia Y MEMORIA, $\mathrm{n}^{\circ} 13$ (2016), 301-330. DOI: http://dx.doi.org/10.19053/20275137.5207 